phase of $\mathrm{CH}_{2} \mathrm{I}_{2}$ [5]. In the polar Fmm2-symmetric phase the dipole moments of all molecules are parallel.

A group of isostructural crystals has been identified for a series of 1,2-dihalotetrafluoroethanes $\mathrm{X}\left(\mathrm{CF}_{2}\right)_{2} \mathrm{Y}(\mathrm{X}=\mathrm{Br}$, $\mathrm{I}$; $\mathrm{Y}=\mathrm{Br}$, I). Despite their isostructurality the molecules behave differently. The $\mathrm{BrCF}_{2} \mathrm{CF}_{2} \mathrm{Br}$ structure is completely ordered, in $\mathrm{ICF}_{2} \mathrm{CF}_{2} \mathrm{I}$ the $-\mathrm{CF}_{2}-\mathrm{CF}_{2}$ - moiety rotate about $\mathrm{I} \cdots \mathrm{I}$ molecular axis, but it orders at pressure higher than $1 \mathrm{GPa}$, and in the $\mathrm{BrCF}_{2} \mathrm{CF}_{2} \mathrm{I}$ structure the $\mathrm{Br}$ and I atoms are disordered. The formation of isostructural crystals by these compounds and different types of molecular disorder can be rationalized by the similar patterns of intermolecular interactions.

In the crystal of dichloroacetic acid $\left(P 2_{1} / n\right)$, molecules are connected by chlorine $\cdots$ chlorine interactions into infinite zigzag chains

While the structures of the series of halogenated methanes and ethanes are clearly governed by halogen $\cdots$ halogen interactions, we encountered also structures where this type of interactions was absent. For example, in the crystal structure of chlorotrimethylsilane $\mathrm{Si}\left(\mathrm{CH}_{3}\right)_{3} \mathrm{Cl}\left(\mathrm{Pmn}_{1}\right)$, no such intermolecular contacts shorter than $5 \AA$ have been observed [6].

[1] Legon A.C., Angew. Chem. Int. Ed., 1999, 38, 2686.

[2] Metrangolo P., Resnati R., Chem. Eur. J., 2001, 7, 2511.

[3] Grineva O.V., Zorky P.M., Zh. Fiz. Khim., 1998, 72, 714.

[4] Podsiadło M., Dziubek K., Katrusiak A., Acta Cryst., 2005, B61, 595.

[5] Podsiadło M., Dziubek K., Szafrański M., Katrusiak A., Acta Cryst., 2006, B62, 1090.

[6] Gajda R., Dziubek K., Katrusiak A., Acta Cryst., 2006, B62, 86.

\section{MS27 O4}

The influence of environment on structure: Polymorphs of $\gamma$-aminobutyric acid (GABA) and gabapentin. D. C. Levendis and H. Reece, Molecular Sciences Institute, School of Chemistry, University of the Witwatersrand, PO WITS 2050, Johannesburg, South Africa. Email: demi@chem.wits.ac.za

\section{Keywords: GABA, gabapentin, polymorph, solvate}

The neurotransmitter amino acid $\gamma$-aminobutyric acid (GABA) has previously been found to exist as two polymorphs: a monoclinic and a tetragonal form. The molecular conformation of GABA in each of these forms is significantly different, influenced by both strong intermolecular $\mathrm{N}-\mathrm{H} \cdots \mathrm{O}=\mathrm{C}$ and weak $\mathrm{C}-\mathrm{H} \cdots \mathrm{N}$ or $\mathrm{C}-\mathrm{H} \cdots \mathrm{O}$ hydrogen bonds. Changes in the environment (solvent, amino acids in the solutions, temperature) are known to influence the crystallization of simple amino acids [1] and recently strategies to form co-crystals of GABA have been described [2]. In this work we report on the crystallization of a novel hexagonal form of GABA, which occurs as an ethanol solvate. The long, needle shaped crystals $\left(\mathrm{P}_{2}: \mathrm{a}=\right.$ 15.9164(4), b = 15.9164(4), c = 7.8769(4) $\AA$ ) retain their structure until $1-2^{\circ} \mathrm{C}$ before melting $\left(\sim 190^{\circ} \mathrm{C}\right)$. There are two crystallographically independent GABA molecules in the unit cell with disordered ethanol molecules tightly bound in the hexagonal channels. The ethanol is released from the hexagonal channels (Fig. 1), close to the melting point, as clearly detected by hot stage microscopy. The structures and hydrogen bonding networks in two previously unreported monoclinic polymorphs of the GABA analogue, 1-aminomethyl-1-cyclohexane-acetic acid (gabapentin) will also be reported in this paper.

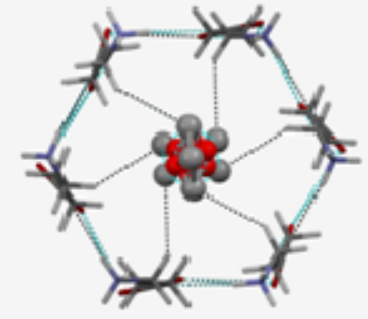

Figure 1. A projection down the $\mathrm{c}$ axis of the new hexagonal form of GABA showing disordered ethanol molecules in the $6_{2}$ hexagonal channels.

[1] V.Yu. Torbeev, E. Shavit, I. Weissbuch, L. Leiserowitz and M. Lahav, Crystal Growth \& Design, 2005, 5(6), 2190-2196.

[2] M. Wenger and J. Bernstein, Angew. Chem. Int. Ed. 2006, 45, $7966-7969$.

\section{MS27 O5 \\ In-situ cocrystallisation combined with Raman spectroscopy Michael T. Kirchner, Roland Boese Department of Chemistry, University of Duisburg-Essen, Germany. E-mail:michael.kirchner@uni-due.de}

Keywords: crystal growth, hydrogen bonds in organic crystals, Raman spectroscopy

Fast characterization of the products from cocrystallisation experiments is highly important since there are no general rules for appropriate growth conditions. Therefore a large number of experiments have to be performed to find the right conditions which favor the growth of a cocrystal over the growth of the individual components. For in-situ crystallization on a single crystal diffractometer this is especially important as characterization by diffraction is time consuming. We therefore incorporated a Raman probe into our in-situ laser zone melting apparatus. First results from systems containing acetylene, dioxane, formamide, formic acid and formaldehyde are highly promising. Already in the Raman spectra of the liquid mixtures we found hints to the formation of molecular aggregates which might be precursors of the cocrystals. After solidification and zone melting growth we used Raman spectroscopy to identify the formation of a cocrystal. Basic research in cocrystal formation is of increasing interest to pharmaceutical science as cocrystals of active pharmaceutical ingredients can have advantageous properties. 